\title{
Factors affecting the dissociation of metal ions from humic substances
}

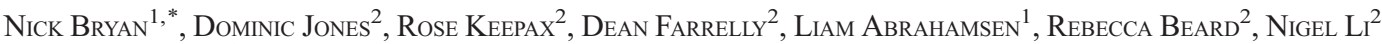 \\ AND GEORGE WeIR ${ }^{1}$ \\ 1 National Nuclear Laboratory, 5th Floor, Chadwick House, Birchwood, Warrington WA3 6AE, UK \\ 2 Centre for Radiochemistry Research, School of Chemistry, University of Manchester, Manchester M13 9PL, UK
}

[Received 10 October 2014; Accepted 3 March 2015; Associate Editor: Nicholas Evans]

\section{ABSTRACT}

Previously, it has been suggested that metal ions complexed to humic acid in the environment might show slower dissociation than those added to humic substances in the laboratory, which has serious implications for the transport of radionuclides in the environment. The dissociation of lanthanide and anthropogenic actinide ions from humic substance complexes has been studied as a function of humic concentration and metal ion:humic concentration ratio. The results suggest that the apparently slower kinetics observed for metal ions complexed in the environment are probably due to the large humic concentrations that are used in those studies. Further, there is no evidence that the dissociation rate constant varies at very low metal ion concentrations. Although humic samples size-fractionated by ultrafiltration showed that more metal may be bound non-exchangeably, there was no evidence for different rate constants. Ultrafiltration of Eu(III)/humic acid mixtures did show a shift in Eu from smaller to larger fractions over a period of two days. Therefore, the results suggest that dissociation rate constants determined in the laboratory at metal ion concentrations higher than those expected in the environment may be used in predicting radionuclide mobility, provided that the humic acid concentration is in the range expected at the site.

KeYwords: dissociation, metal ions, humic substances, lanthanide, actinide.

\section{Introduction}

WHEN a metal ion first encounters a humic molecule or colloid, it is initially bound 'exchangeably' (Bryan et al., 2007). In this state it is bound strongly, but in the presence of a stronger binding site on a mineral surface, it may dissociate quickly, and be retarded (Bryan et al., 2007). Over time, exchangeably-bound metal ions transfer to the 'non-exchangeable' fraction. Here, the metal ion is isolated from solution phase chemistry, and the

* E-mail: nick.bryan@nnl.co.uk

DOI: 10.1180/minmag.2015.079.6.15 first-order rate of dissociation is independent of the strength of the competing sink (Bryan et al., 2007). There is a continuum of dissociation rate constants (Bryan et al., 2007) and a distinct, most slowly dissociating fraction (with a single first-order rate constant) which represents a significant part of the bound metal.

It has been shown that the origin of the humic substance has little effect on the dissociation rate constant (Monsallier et al., 2003). They are also insensitive to $\mathrm{pH}$ and the presence of competing ions (King et al., 2001), although Lippold et al. (2012) have found that high concentrations of $\mathrm{Al}^{3+}$ can suppress the amount of other metal ions bound. Metal ion chemistry seems to have little effect on
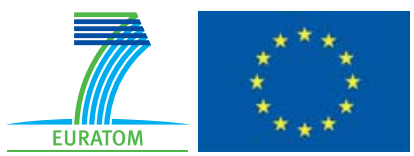

The publication of this research has been funded by the European Union's European Atomic Energy Community's (Euratom) Seventh Framework programme FP7 (2007-2013) under grant agreements $n^{\circ} 249396$, SecIGD, and $n^{\circ} 323260$, SeclGD2. 
the dissociation rate constant (Monsallier et al., 2003; Bryan et al., 2007).

All studies have found that the first order dissociation rate constant is the most critical parameter for radionuclide transport (Bryan et al., 2007), and that in the absence of non-exchangeable binding or in systems where the ion has sufficient time to dissociate, rapid transport of radionuclides is not expected. The critical factor in determining the extent of transport is the product of the dissociation rate constant and the transport residence time (Bryan et al., 2007).

The mechanism responsible for the slow dissociation is uncertain. Previously, diffusion of metal ions from distinct exchangeable to nonexchangeable sites has been suggested (e.g. Warwick et al., 2000), although some recent evidence from Lippold et al. (2012) suggests that this is probably incorrect. Alternatives include rearrangement of humic structure around a fixed coordination site (Lippold et al., 2012). It has also been suggested that metal ions might form bridges between humic species, which could make them slower to dissociate (Geckeis et al., 2002).

It has been suggested (Geckeis et al., 2002; Bryan et al., 2006) that metal ions bound to humic substances in the environment may show slower dissociation than complexes made in the laboratory. In previous work (Bryan et al., 2006), complexes of anthropogenic actinides were isolated from soil collected from Cumbria UK (UK nat. grid ref. SD113964). In that study, the extraction $\mathrm{pH}$ was high ( $\mathrm{pH}$ 10-12). Here, Am complexes were extracted at lower $\mathrm{pH}(8)$. The dissociation of $\mathrm{Eu}(\mathrm{III})$ and $\mathrm{Am}$ (III) from Aldrich humic acid across wide ranges of humic concentration and metal: humic ratio are also reported here as is the effect of humic fraction size on the dissociation rate constant.

\section{Materials and experimental}

All experiments were performed in sealable polypropylene containers. All water was deionized $(18 \mathrm{M} \Omega)$, and all reagents were analytical grade. In the text below, 'natural' refers to metal ions present in the soil sample at collection, whilst 'synthetic' complexes are those formed with metal ions added in the laboratory.

Several distinct experiments were performed. The dissociation rate constants and amounts in the most slowly dissociating fractions were determined for:
(1) Am complexed to humic acid extracted from a Cumbrian soil (natural Am);

(2) Am and $\mathrm{Eu}$ added to the extracted Cumbrian soil humic acid (synthetic Am and Eu);

(3) Am and $\mathrm{Eu}$ added to Aldrich humic acid (Aldrich synthetic Am and Eu);

(4) Am and Eu added to size-fractionated Aldrich humic acid (Aldrich synthetic Am and Eu).

In a $5^{\text {th }}$ experiment, Eu was allowed to interact with Aldrich humic acid. After various equilibration times, the sample was size fractionated and the distribution determined. Each of the experiments is described in detail below.

\section{(1) Dissociation of natural Am from Cumbrian humic acid (Table 1)}

Soil was collected from Cumbria, UK (UK nat. grid ref. SD113964). This soil has been characterized previously (Livens and Singleton, 1991). It is an alluvial gley, with organic, $\mathrm{Fe}, \mathrm{Mn}$ and $\mathrm{Al}$ contents of $3 \%, 4.4 \%, 0.88 \%$ and $5.35 \%$, respectively. Further details of soil from this location and its radionuclide content are given in Livens and Singleton (1991). The sample was sieved (2 mm) and mixed with deionized water $(5 \mathrm{~g}: 10 \mathrm{ml})$. $\mathrm{NaOH}$ was added to raise the $\mathrm{pH}$ of the solution to 8.2 , which is in the range of $\mathrm{pH}$ studied by Geckeis et al. (2002). The mixture was covered and stirred for 3 days; the $\mathrm{pH}$ remained in the range $8.2 \pm 0.1$. The solution contained humic acid extracted from the soil, and had a concentration of $140 \mathrm{ppm}$; the concentration was determined by UV analysis of standard solutions $(\mathrm{pH}=6.0 ; 400 \mathrm{~nm})$. The solution was centrifuged (3000 rpm, $1480 \mathrm{RCF}$, $45 \mathrm{~min}$ ) and the supernatant adjusted to $\mathrm{pH}$ 6. The ${ }^{241} \mathrm{Am}$ activity was determined by $\gamma$-ray spectrometry.

First-order dissociation rate constants were determined by the resin competition method (Monsallier et al., 2003), where humic/metal complexes are exposed to an excess of a strong metal ion binding resin, in this case cellulose phosphate, such that equilibrium lies heavily on the side of the resin. Cellulose phosphate sodium salt resin (Sigma Aldrich) was conditioned in batch mode by stirring for $24 \mathrm{~h}$ in electrolyte $\left(\mathrm{NaClO}_{4}\right.$ $0.1 \mathrm{M} ; \mathrm{pH}=6.0 \pm 0.1$, adjusted with $\mathrm{HClO}_{4} /$ $\mathrm{NaOH}$ ), in the ratio $1 \mathrm{~g}$ resin to $10 \mathrm{ml}$ electrolyte. In the absence of humic acid, all metal ion is removed from solution within a few hours. There is no sorption of humic material by this resin. $50 \mathrm{~g}$ of resin was added to $500 \mathrm{ml}$ aliquots of extract solution. These samples were shaken at $25^{\circ} \mathrm{C}$, and 


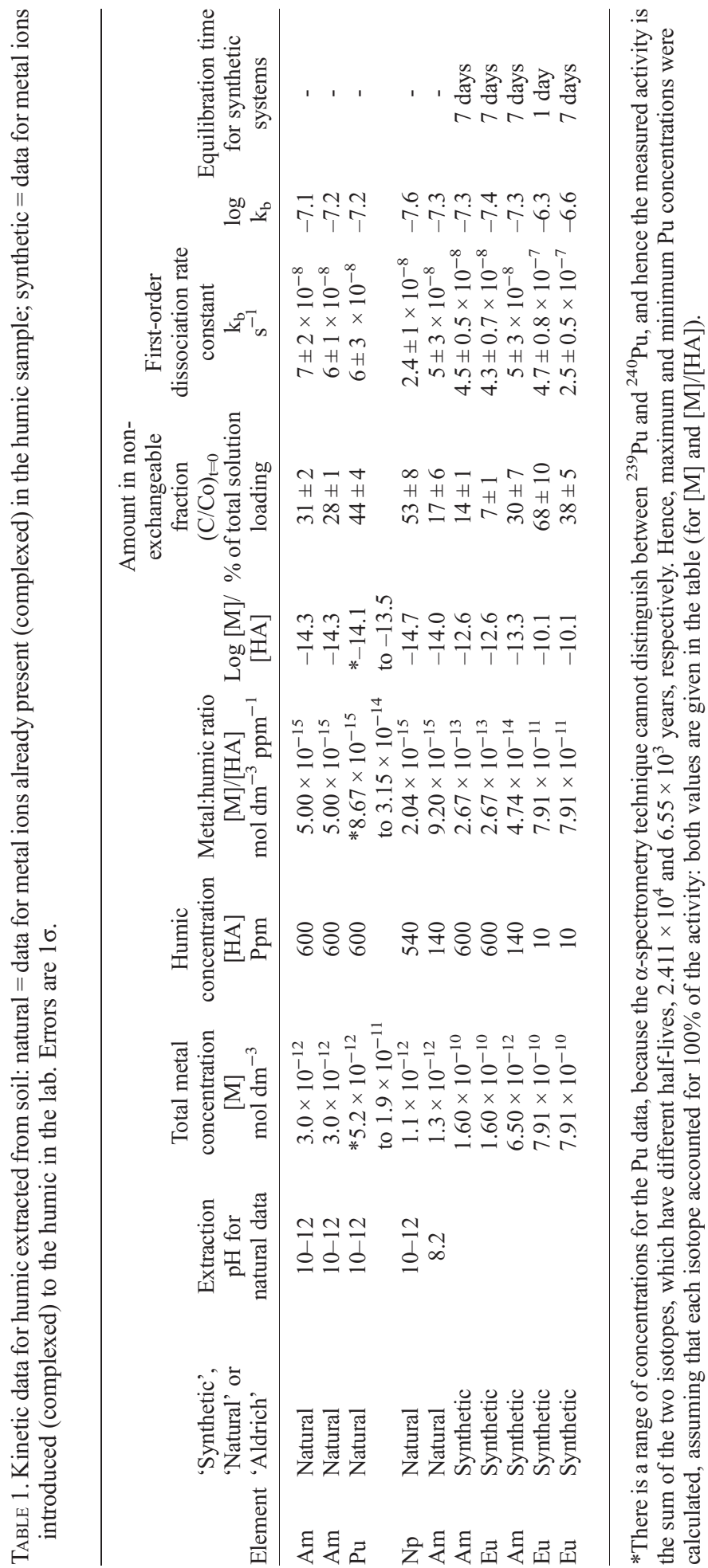


at intervals, aliquots of the solution $(100 \mathrm{ml})$ were removed and analysed for natural Am. Following analysis, the $100 \mathrm{ml}$ aliquots were returned to the experiment, and the system mixed such that the volume that had been removed for analysis was mixed with the rest.

\section{(2) Dissociation of synthetic Am and Eu from Cumbrian humic acid (Table 1)}

To separate samples of the $140 \mathrm{ppm}$ soil extract solution, ${ }^{241} \mathrm{Am}$ or ${ }^{152} \mathrm{Eu}$ were added to form 'synthetic' complexes $\left(\mathrm{NaClO}_{4} 0.1 \mathrm{M} ; \mathrm{pH}=6.0 \pm\right.$ 0.1 ). These were allowed to equilibrate for one week before their dissociation was measured with fresh batches of resin (using the method above). In a different experiment, the original $140 \mathrm{ppm}$ extract solution was diluted with deionized water to give $[\mathrm{HA}]=10 \mathrm{ppm}$ (dilution factor of 14 from original $140 \mathrm{ppm}$ solution), before ${ }^{152} \mathrm{Eu}$ was added and allowed to equilibrate for one week, and the dissociation rate was determined (as above).

\section{(3) Dissociation of synthetic Am from Aldrich humic acid (Table $3 A$ and $B$ )}

In a separate series of experiments, 'synthetic' complexes of ${ }^{152} \mathrm{Eu}$ and ${ }^{241} \mathrm{Am}$ were prepared at $\mathrm{pH}$
$6.0 \pm 0.1\left(\mathrm{NaClO}_{4} 0.1 \mathrm{M}\right)$ with Aldrich humic acid (which was used without purification), and the dissociation rate constants determined in the same way as above, but using $1 \mathrm{~g}$ of Cellphos resin (Sigma Aldrich) to $10 \mathrm{ml}$ of solution. All of the Eu experiments contained ${ }^{152} \mathrm{Eu}\left(0.13 \mathrm{kBq} \mathrm{ml}^{-1}\right)$, and stable $\mathrm{Eu}$, either present in the radiotracer solution or added as a standard solution of $\mathrm{Eu}\left(\mathrm{NO}_{3}\right)_{3}$, to give a total $\mathrm{Eu}$ concentration in the range of $7.9 \times$ $10^{-10}-5 \times 10^{-5} \mathrm{M}$. The ${ }^{241} \mathrm{Am}$ experiment used a total ${ }^{241} \mathrm{Am}$ concentration of $6.7 \times 10^{-15} \mathrm{M}$. The humic concentration in these experiments was in the range $10-500 \mathrm{ppm}$.

(4) Dissociation of synthetic Eu from sizefractionated Aldrich humic acid (Table 3C)

Aldrich humic stock solution was ultra-filtrated sequentially through Millipore membranes (regenerated cellulose: 100, 10 and $3 \mathrm{kDa}$ ) using a Millipore Amicon 8200 stirred ultrafiltration cell, connected to a pressurized nitrogen gas cylinder at 75 psi. ${ }^{152} \mathrm{Eu}$ was added to solutions of the fractions, and the dissociation studied as above. In all of the Aldrich experiments, the metal ions were allowed to equilibrate with the humic material for a period of 7 days prior to dissociation.

TABLE 2. Kinetic data used in Figs 1 and 2 from other authors: Eu data from King et al. (2001) for humic and fulvic acids; Eu data from Geckeis et al. (2002) for a purified humic sample. Th data from Davis et al. (2000). Errors are $1 \sigma$.

\begin{tabular}{|c|c|c|c|c|c|c|c|}
\hline Reference & $\begin{array}{c}\text { Humic concentration } \\
{[\mathrm{HA}]} \\
\mathrm{ppm}\end{array}$ & $\begin{array}{l}{[\mathrm{M}] /[\mathrm{HA}]} \\
\mathrm{mol} \mathrm{dm}^{-3} \\
\mathrm{ppm}^{-1}\end{array}$ & $\begin{array}{c}\log [\mathrm{M}] / \\
{[\mathrm{HA}]}\end{array}$ & $\mathrm{pH}$ & Equilibration time & $\begin{array}{l}\mathrm{k}_{\mathrm{b}} \\
\mathrm{s}^{-1}\end{array}$ & $\begin{array}{l}\log \\
k_{\mathrm{b}}\end{array}$ \\
\hline King et al. (2001) & 10 & $1.14 \times 10^{-8}$ & -7.9 & 6.5 & 9 days & $\begin{array}{c}2.2 \pm 0.5 \times \\
10^{-7}\end{array}$ & -6.7 \\
\hline King et al. (2001) & 10 & $1.14 \times 10^{-8}$ & -7.9 & 6.5 & 131 days & $\begin{array}{c}1.5 \pm 0.2 \times \\
10^{-7}\end{array}$ & -6.8 \\
\hline King et al. (2001) & 60 & $1.9 \times 10^{-9}$ & -8.7 & 6.5 & 9 days & $\begin{array}{c}8 \pm 3 \times \\
10^{-8}\end{array}$ & -7.1 \\
\hline King et al. (2001) & 10 & $1.14 \times 10^{-8}$ & -7.9 & 6.5 & 9 days & $\begin{array}{c}2.3 \pm 0.3 \times \\
10^{-7}\end{array}$ & -6.6 \\
\hline King et al. (2001) & 10 & $1.28 \times 10^{-7}$ & -6.9 & 6.5 & 9 days & $\begin{array}{c}3.3 \pm 0.3 \times \\
10^{-7}\end{array}$ & -6.5 \\
\hline Geckeis et al. (2002) & $\begin{array}{c}30 \\
\text { (purified) }\end{array}$ & $3.33 \times 10^{-8}$ & -7.5 & 8 & $\begin{array}{l}\text { Average for } 1 \mathrm{~h}-42 \\
\text { days }\end{array}$ & $\begin{array}{c}2.1 \pm 0.3 \times \\
10^{-6}\end{array}$ & -5.7 \\
\hline Davis et al. (2000) & 30 & $3.33 \times 10^{-9}$ & -8.5 & 7.8 & $\begin{array}{l}\text { Average rate for } 1-4 \\
\text { days }\end{array}$ & $\begin{array}{c}1.6 \pm 0.6 \times \\
10^{-7}\end{array}$ & -6.8 \\
\hline Davis et al. (2000) & 30 & $3.33 \times 10^{-16}$ & -15.5 & 6.4 & $\begin{array}{l}\text { Average rate for } 1-4 \\
\text { days }\end{array}$ & $\begin{array}{c}3 \pm 1 \times \\
10^{-7}\end{array}$ & -6.6 \\
\hline
\end{tabular}




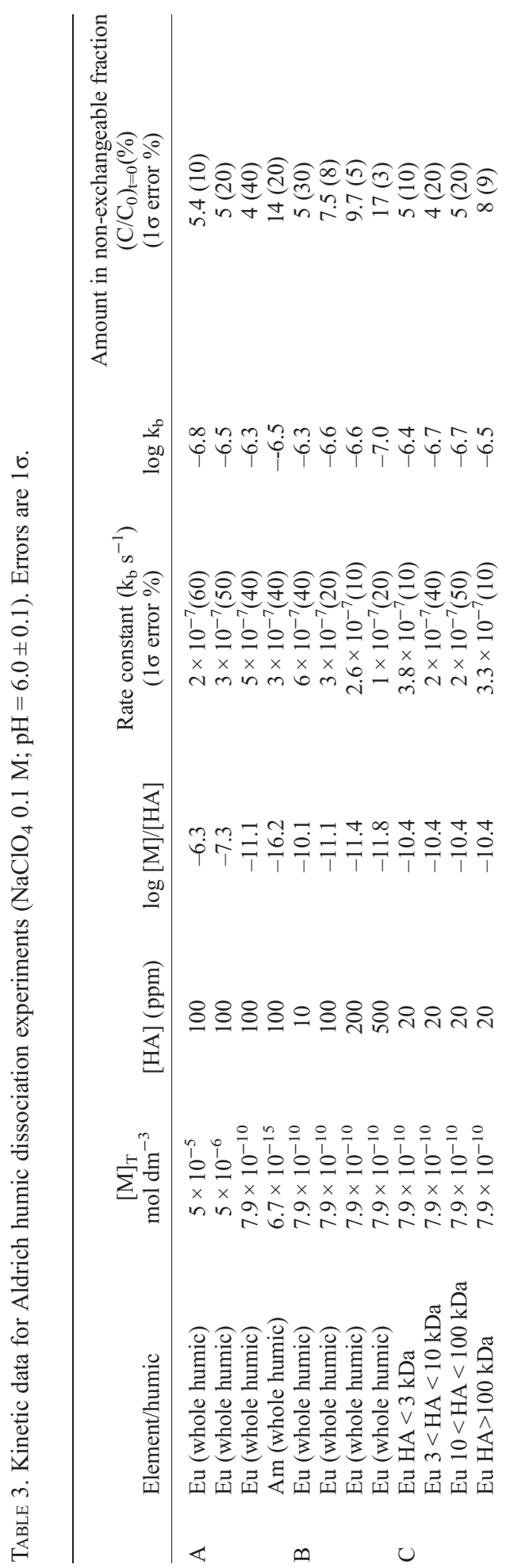

\section{Size distribution of Eu complexed by Aldrich humic acid (Fig. 4)}

In a separate experiment, $100 \mathrm{ppm}$ Aldrich humic acid europium mixtures were prepared $\left(\mathrm{NaClO}_{4} 0.1 \mathrm{M}\right.$; $\mathrm{pH}=6.0 \pm 0.1 ;\left[{ }^{152} \mathrm{Eu}\right]=0.13 \mathrm{kBq} \mathrm{ml}{ }^{-1} ;\left[\mathrm{Eu}_{\text {Total }}\right]=$ $7.9 \times 10^{-10} \mathrm{M}$ ). The samples were left for 1,4 and 14 days to equilibrate before being ultrafiltered, exactly as above. The Eu concentration in each fraction was determined by gamma ray spectrometry.

\section{Results and discussion}

The rate constants and amounts in the nonexchangeable fraction for the soil extract experiments from this study and Bryan et al. (2006) are shown in Table 1. Some literature data are given in Table 2, and Table 3 gives data for the experiments with Aldrich humic acid. In all three tables, the first-order dissociation rate constants for the most slowly dissociating fraction (non-exchangeable) $\left(\mathrm{k}_{\mathrm{b}}\right)$ are given. For the data from this study, the amounts of the metal in that fraction are also given.

The dissociation rate constants are within error for all of the 'natural' experiments, which suggests that the mechanism responsible for the non-exchangeable effect is common to all of the metal ions. The 'natural' Am data in Table 1 show that changing the $\mathrm{pH}$ of the extraction between 8.2 and 12 does not affect the dissociation rate constant. The most important result from the data in Table 1 is that the rate constants for the 'synthetic' experiments at the same humic concentration as the 'natural' systems are within error, and the rate constant does not depend upon whether metal was bound in the laboratory or the environment. Instead, an increase in rate constant is observed when the concentration of the humic is reduced to $10 \mathrm{ppm}$ (compare last two rows of Table 1 with the others). There are two factors that could be responsible for this change: humic concentration alone or metal to humic concentration ratio.

Figure 1 shows the dissociation rate constant plotted versus humic concentration for the data in Tables 1 and 3. Literature data for other f-element metal ions are also plotted for comparison (from Table 2). There does appear to be a decrease in the rate constant as [HA] increases. There is a single outlier in the data. This is a fluoride-purified humic sample, whilst the rest are for samples not treated with $\mathrm{F}^{-}$. A difference in dissociation behaviour between purified and unpurified samples has been observed before (Monsallier et al., 2003). Artinger et al. (2002) have suggested that mixed inorganic and organic species might be responsible for the 


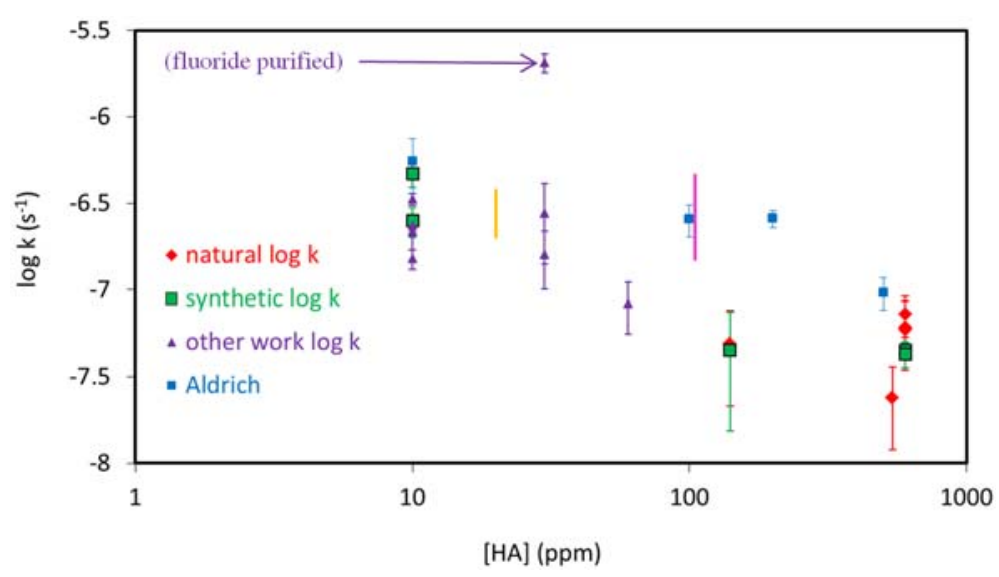

FIG. 1. First-order dissociation rate constant $v s$. humic concentration for data in Tables 1 (red diamonds and green squares) and 2 (purple triangles); Pink vertical line $=$ range of data from Table 3 Part B at 100 ppm for Aldrich humic; Gold vertical line $=$ range of data from Table 3 Part $\mathrm{C}$ at $20 \mathrm{ppm}$ for Aldrich humic size fractions; Aldrich data from

Table 3 Part A plotted as blue squares.

non-exchangeable effect. The fluoride purification process may disrupt these species, and so affect the dissociation rate.

Figure 2 shows the dissociation rate constant plotted against the ratio of metal to humic for the data in Tables 1-3. There is no clear relationship between the rate constant and the ratio. The data plotted in the figure are for a variety of humic samples and data from different groups with different techniques, and it was possible that this could affect the dissociation. However, the data in Table 3 Section A are for the same humic and have a constant humic concentration. Americium was used for the lowest concentration, because the stable carrier concentration in the Eu radiotracer solution did not permit such a low value. These data are plotted in Fig. 2 as blue squares with a connecting line and they confirm that there is no effect of metal: humic ratio on the dissociation rate constant. Figure 1 helps to explain the distribution of data

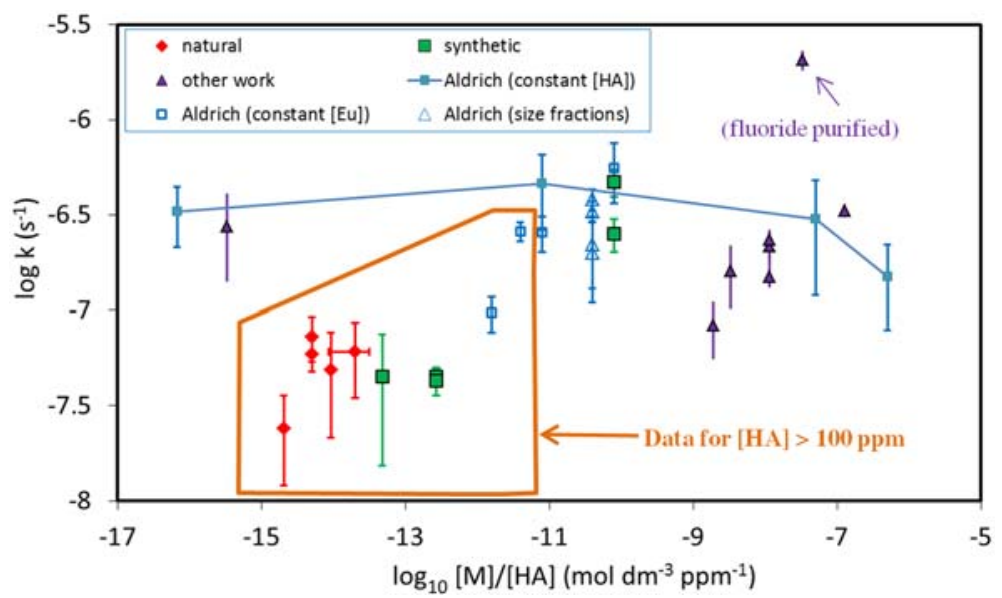

FIG. 2. First-order dissociation rate constant $v s$. metal to humic concentration ratio for data in Tables 1 (red diamonds and green squares) and 2 (purple triangles). Aldrich data from Table 3 (Parts A and B, whole humic, blue squares; Part C, humic size fractions, blue triangles). Error bars are $\pm 1 \sigma$. 


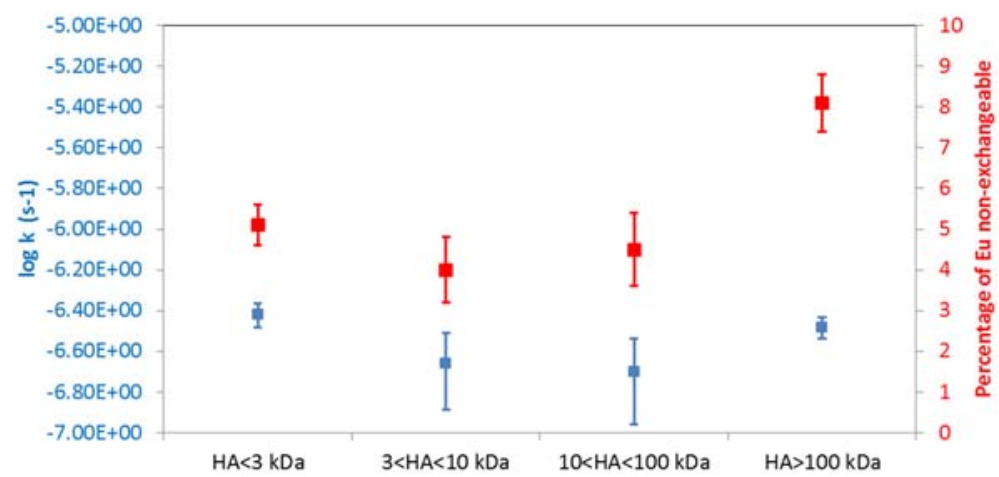

FIG. 3. Log dissociation rate constant (blue squares, left axis) and percentage in non-exchangeable fraction (red squares, right axis) $v s$. humic fraction size. Error bars are $\pm 1 \sigma$.

points in Fig. 2. There is a group of data with lower rate constants at low $[\mathrm{M}] /[\mathrm{HA}]$ values that are detached from the rest. The data for humic concentrations greater than $100 \mathrm{ppm}$ are circled in brown in Fig. 2, which includes the entire outlying group. Hence, their separation may be due to their high concentrations. Considering the remainder of the data, there is no apparent correlation with [M]/ [HA]. It is significant that the only two points from Table 1 outside of the circled group are those with a lower humic concentration (10 ppm).

Figure 3 shows the variation in rate constant and amount in the non-exchangeable with fraction size. There is no significant difference in the rates, but the largest fraction has most non-exchangeably bound. King et al. (2001) found that the fulvic and humic dissociation rate constants are similar but that the amount of metal bound non-exchangeably is lower for the notionally smaller fulvics. The data in Table 3 are consistent with this.

Figure 4 shows the amounts of $\mathrm{Eu}^{3+}$ that were measured in each $\mathrm{HA}$ size fraction after $\mathrm{HA}$ and $\mathrm{Eu}^{3+}$ were left for different equilibration times. After $24 \mathrm{~h}$ equilibration, the $3<\mathrm{HA}<10 \mathrm{kDa}$ fraction dominates. After two days the $10<\mathrm{HA}<100 \mathrm{kDa}$ fraction has bound more metal ions and the amount in the $3<\mathrm{HA}<10 \mathrm{kDa}$ fraction has reduced. The smallest size fraction is responsible for a minority of the Eu binding over the first week of contact but thereafter, it plays no role. The most striking result is that the $\mathrm{HA}>100 \mathrm{kDa}$ fraction dominates the distribution from four days. The results show a distinct shift from the $<10 \mathrm{kDa}$ size range to the $>10 \mathrm{kDa}$ size range (largely) over a

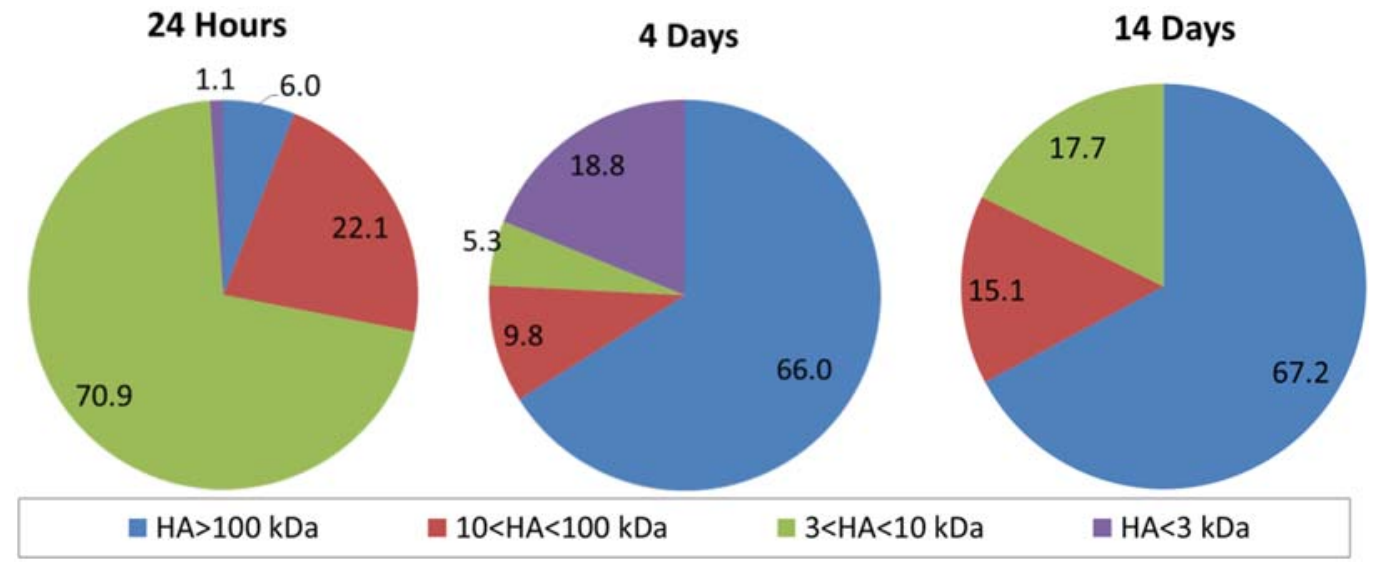

FIG. 4. Distribution of Eu between humic size fractions as a function of pre-equilibration time ([HA] $=100 \mathrm{ppm} ; \mathrm{NaClO}_{4}$ $\left.0.1 \mathrm{M} ; \mathrm{pH}=6.0 \pm 0.1 ;\left[{ }^{152} \mathrm{Eu}\right]=0.13 \mathrm{kBq} \mathrm{ml}^{-1} ;\left[\mathrm{Eu}_{\mathrm{Total}}\right]=7.9 \times 10^{-10} \mathrm{M}\right)$. 
period of a few days. It has been observed that the transfer from exchangeable to non-exchangeable takes place over a time period of a few days to a week (King et al., 2001; Schuessler et al., 2000; Bryan et al., 2007; Lippold et al., 2012), and it is tempting to associate the transfer of metal from exchangeable to non-exchangeable with the shift in distribution.

\section{The mechanism}

For the natural systems studied here, it seems that the slower dissociation kinetics are due to the very high humic concentrations that were required to give actinide concentrations large enough to allow determination. There is no effect of complexation in the environment, or of the associated long contact times. Geckeis et al. (2002) observed a further, more resistant fraction that did not dissociate significantly on a timescale of 100 days, and appeared to be pseudo-irreversibly bound. This inert component was associated with very large material $(\sim 35 \mathrm{~nm})$, consisting of an inorganic core, coated with humic. No evidence for such an inert component was found for the natural samples studied here. There are two possible explanations for this difference in behaviour between the natural systems in the two studies. It could be that there is an intrinsic difference in the humic substances, and that some humic samples will complex metal ions pseudo-irreversibly. Alternatively, the inert fraction perhaps forms part of the matrix of the inorganic component of the large species. If this is the case, then it is possible that radionuclides that are complexed from solution might not develop this inert behaviour.

The dissociation rate constant is independent of metal ion chemistry, and given that simple organic ligands, such as citrate, do not show non-exchangeable behaviour, it seems likely that the effect is due to some special property of the humic substances. Altogether, the results of the experiments do suggest that humic concentration is controlling the dissociation rate constant, rather than the metal: humic ratio. Previously, it has been suggested that the movement of metal could be associated with diffusion from a surface available binding site to one 'hidden' within the humic structure. The work of Lippold et al. (2012) suggests that this is not the case. Further, if diffusion in and out of humic structures were controlling the kinetics, then the larger fractions might be expected to show different rate constants, and this is not the case here (Fig. 3). It is thought that humic molecules in solution are subject to a significant degree of dynamic aggregation (e.g. Conte and Piccolo, 1999), and it has been suggested that these aggregation processes could result in a metal ion, which was initially on the surface of a humic molecule or pre-existing aggregate and so exposed to the bulk solution and available, becoming trapped within the structure of an aggregate, as its host humic molecule takes place in the dynamic aggregation process (Keepax et al., 2002). This would render it unavailable for instantaneous interaction, and so it would be nonexchangeable. Further, as the aggregation process is thought to be dynamic, with aggregates constantly forming and dissociating, the non-exchangeable metal ion would eventually be released from the structure for interaction with the bulk solution, but that process would be slow. It has been shown previously that a significant increase in aggregation takes place, as humic concentration increases from the $10 \mathrm{ppm}$ region to $>100 \mathrm{ppm}$ (e.g. Reid et al., 1991; Jones and Bryan, 1998). If the mechanism described above is correct, then an effect on the dissociation behaviour would be expected, and this is what is observed (Fig. 1). Further, if the development of non-exchangeable binding is associated with metal ion trapping within aggregates, we would expect to see a transfer from smaller isolated humic species to larger aggregates on the same timescale, which has also been observed here (Fig. 4). Hence, it seems plausible that dynamic aggregation processes are responsible for the non-exchangeable effect.

The addition of metal ions to humic substances has been shown to promote aggregation (e.g. Bryan et al., 2001a,b), and so the insensitivity of the dissociation kinetics to the $[\mathrm{M}]:[\mathrm{HA}]$ ratio might seem surprising. However, Bryan et al. (2001a,b) found that for the trivalent lanthanide $\mathrm{La}^{3+}$, there was a threshold concentration below which there was no significant effect: this was $1.4 \times 10^{-5} \mathrm{~mol}$ $\mathrm{dm}^{-3}$ at $10 \mathrm{ppm} \quad\left([\mathrm{M}] /[\mathrm{HA}]=1.4 \times 10^{-6} \mathrm{~mol}\right.$ $\left.\mathrm{dm}^{-3} ; \log _{10}[\mathrm{M}] /[\mathrm{HA}]=-5.9\right)$. Most of the metal ion concentrations considered here are very low. Only system A in Table 3 approaches this value, but is still below it. Hence, the lack of an effect may result from the fact that the bulk aggregation of the humic sample has not been affected significantly by the presence of the metal ions themselves. Metal ions may form bridges between humic molecules (Geckeis et al., 2002), even at low metal ion concentrations, but those metal-humic bonds themselves do not seem to control the dissociation kinetics, since metal ions with very different chemistries have the same dissociation rate constants. It is possible that if there were sufficient 
metal ions to disturb the dynamic aggregation of the humic sample, then an effect would be observed.

\section{Summary and conclusions}

The metal ion dissociation rate constant does not seem to depend upon metal ion chemistry or metal: humic ratio. Humic concentration and the associated effect on dynamic aggregation is important. It is likely that the non-exchangeable effect is associated with the trapping of metal ions within aggregates.

For the sample studied here, there is no evidence that complexation in the environment or the associated long contact times have any effect on the rate of dissociation. Therefore (in this case at least), laboratory synthetic studies can provide rate data for calculations of metal ion mobility in the environment, but those measurements should be made in the same range of humic concentration as is expected at the site.

\section{Acknowledgement}

The authors would like to thank the European Union (FUNMIG FP6-516514) and the National Nuclear Laboratory for funding to support this work.

\section{References}

Artinger, R., Schuessler, W., Schaefer, T. and Kim, J.I. (2002) A kinetic study of Am(III)/humic colloid interactions. Environmental Science \& Technology, 36, 4358-4363.

Bryan, N.D., Jones, M.N., Birkett, J. and Livens, F.R. (2001a) The application of a new method of analysis of ultracentrifugation data to the aggregation of a humic acid by cupric ions. Analytica Chimica Acta, 437, 281-289.

Bryan, N.D., Jones, M.N., Birkett, J. and Livens, F.R. (2001b) Aggregation of humic substances by metal ions measured by ultracentrifugation. Analytica Chimica Acta, 437, 291-308.

Bryan, N.D., Jones, D.M., Keepax, R.E. and Farelly, D. (2006) Non-exchangeable binding of radionuclides by humic substances: A natural chemical analogue. Pp. 32-37 in: Recent Advances in Actinide Science (I. May, R. Alvarez and N. Bryan, editors), Royal Society of Chemistry, Cambridge, UK.

Bryan, N.D., Jones, D.L.M., Keepax, R.E., Farrelly, D.H., Abrahamsen, L.G., Pitois, A., Ivanov, P., Warwick, P. and Evans, N. (2007) The role of humic nonexchangeable binding in the promotion of metal ion transport in the environment. Journal of Environmental Monitoring, 9, 329-347.
Conte, P. and Piccolo, A. (1999) Conformational arrangement of dissolved humic substances. Influence of solution composition on association of humic molecules. Environmental Science \& Technology, 33, 1682-1690.

Davis, J.R., Higgo, J.J.W., Noy, D.J. and Hooker, P.J. (2000) Complexation studies of uranium and thorium with a natural fulvic acid. Pp. 85-100 in: Effects of Humic Substances on the Migration of Radionuclides: Complexation and Transport of the Actinides (G. Buckau, editor), Wissenschaftliche Berichte (FZKA 6524, ISSN 0947-8620), Forschungszentrum Karlsruhe Technik und Umwelt, Karlsruhe, Germay.

Geckeis, H., Rabung, T., Manh, T.N., Kim, J.I. and Beck, H.P. (2002) Humic colloid-borne natural polyvalent metal ions: Dissociation experiment. Environmental Science \& Technology, 36, 2946-2952.

Jones, M.N. and Bryan, N.D. (1998) Colloidal properties of humic substances. Advances in Colloid and Interface Science, 78, 1-48.

Keepax, R.E., Jones, D.M., Pepper, S. and Bryan, N.D. (2002) The effects of humic substances upon radioactivity in the environment. Pp. 143-177 in: Interactions of Microorganisms with Radionuclides (M. Keith-Roach and F.R. Livens, editors), Elsevier.

King, S.J., Warwick, P., Hall, A. and Bryan, N.D. (2001) The dissociation kinetics of dissolved metal-humate complexes. Physical Chemistry Chemical Physics, 3, 2080-2085.

Lippold, H., Eidner, S., Kumke, M. and Lippmann-Pipke, J. (2012) Diffusion, degradation or on-site stabilisation - Identifying causes of kinetic processes involved in metal-humate complexation. Applied Geochemistry, 27, 250-256.

Livens, F.R. and Singleton, D.L. (1991) Plutonium and americium in soil organic matter. Journal of Environmental Radioactivity, 13, 323-339.

Monsallie, J., Schuessler, W., Buckau, G., Rabung, T., Kim, J.I., Jones, D., Keepax, R. and Bryan, N. (2003) Kinetic investigation of Eu(III)-humate interactions by ion exchange resins. Analytical Chemistry, 75, 3168-3174.

Reid, P.M., Wilkinson, A.E., Tipping, E. and Jones, M.N. (1991) Aggregation of humic substances in aqueous media as determined by light-scattering methods. Journal of Soil Science, 42, 259-270.

Schuessler, W., Artinger, R., Kienzler, B. and Kim, J.I. (2000) Conceptual modeling of the humic colloidborne americium(III) migration by a kinetic approach. Environmental Science \& Technology, 34, 2608-2611.

Warwick, P.W., Hall, A., Pashley, V., Bryan, N.D. and Griffin, D. (2000) Modelling the effect of humic substances on the transport of europium through porous media: a comparison of equilibrium and equilibrium/kinetic models. Journal of Contaminant Hydrology, 42, 19-34. 